IMAGEN EN LA PRÁCTICA CLÍNICA

\title{
Siringoma eruptivo en adolescente del sexo femenino
}

\author{
Eruptive syringoma in adolescent of the female sex
}

\section{Gustavo A. Lizardo Castro, ${ }^{1}$ Ixchel A. Vallecillo. ${ }^{2}$}

${ }^{1}$ Pediatra, Sub-especialista en Dermatología Pediátrica, Departamento de Pediatría, Servicio de Dermatología, Hospital Escuela; Universidad Nacional Autónoma de Honduras (UNAH);

${ }^{2}$ Médico Residente Tercer Año, Postgrado de Dermatología, Facultad de Ciencias Médicas UNAH; Tegucigalpa, Honduras.
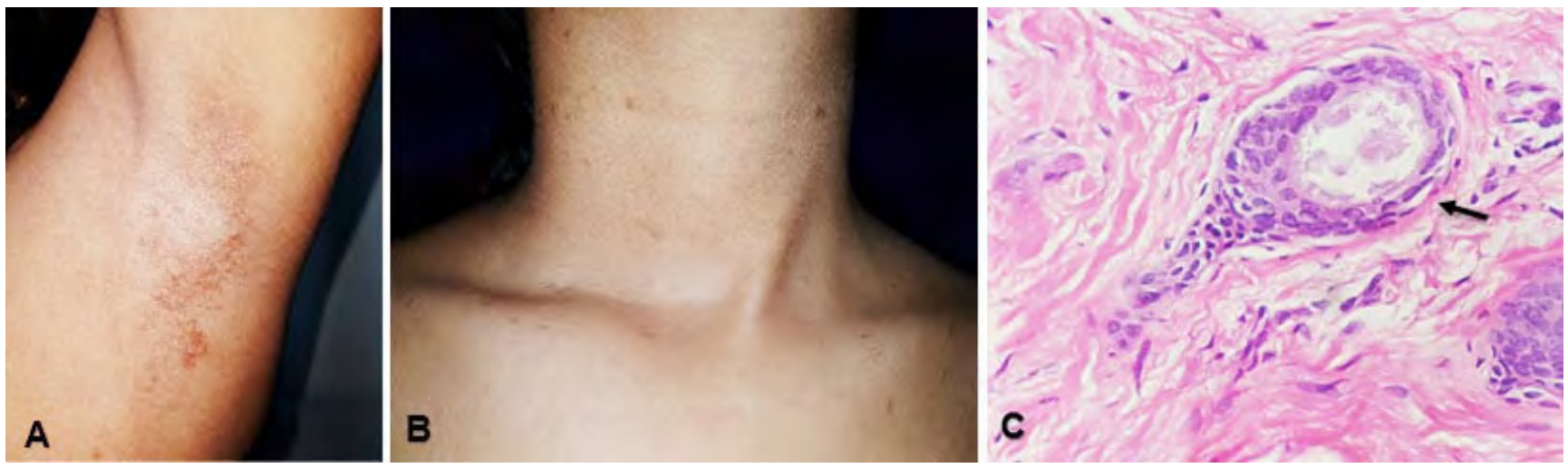

Femenina, 13 años, sin antecedentes de importancia, referida al Servicio de Dermatología, Hospital Escuela, por lesiones levemente pruriginosas en axilas y cuello de dos años de evolución. Se observó múltiples pápulas monomorfas, 2x2 mm, color marrón, localizadas en axilas (Figura A), cuello y parte anterior del tórax (Figura B). Se consideró, enfermedad de Fox Fordyce o quistes vellosos eruptivos. La biopsia de piel (Figura C, hematoxilina\&eosina, 40X) informó: en dermis superior, estructuras ductales revestidas por 2 capas de células cuboidales sin atipia nuclear, en el lumen, material amorfo rosado pálido, PAS positivo, dando un aspecto en "renacuajo" (flecha); consistentes con siringoma. El siringoma es un tumor benigno de glándulas sudoriparas ecrinas, de etiología desconocida. Típicamente afecta adolescentes femeninas con lesiones periorbitarias, menos frecuente en genitales, cuero cabelludo, axilas, cuello y tórax, constituidas por múltiples pápulas asintomáticas, simétricas, color piel, 1-3 mm. Se ha postulado influencia hormonal, por mayor ocurrencia en pubertad, período premenstrual y embarazo. Clasificación: localizado, generalizado, familiar y asociado al síndrome de Down. Diagnóstico: clínico, confirmado por histopatología. Diagnóstico diferencial, depende de su distribución; en este caso la enfermedad de Fox-Fordyce, quistes vellosos eruptivos, verrugas planas. Tratamiento, innecesario; por cosmética, existen opciones médicas y quirúrgicas, con resultados variables.

Recibido: 25-08-2020 Aceptado para publicación 25-01-2021

Dirección para correspondencia: Dr. Gustavo Lizardo

Correo electrónico: glizardoc@yahoo.com 